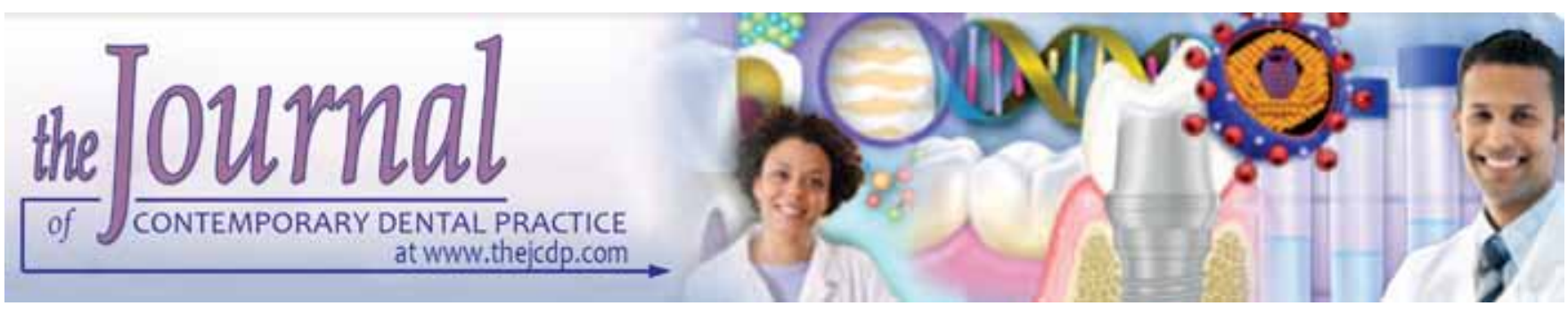

\title{
A Comparative Clinical Evaluation of Diet Intake and Effect of Various Nutritions on Aggressive Periodontitis Patients
}

\author{
Sagar Arjun Mapare, P Krishna Rao, R Vamshidhar Reddy, MG Manoj Kumar, VSS Chandana Gorthi,
} PV Krishnam Raju

\section{ABSTRACT}

Aim: The aim of this study is to investigate the effect various dietary nutrients in aggressive periodontitis patients.

Materials and methods: A total of 85 patients were selected and divided into two groups, 45 patients are with aggressive periodontitis and 40 patients are healthy. Periodontal parameters such as oral hygiene index, Russels periodontal index and radiograph were taken. The food consumption survey was conducted in all the households of subjects both in control and experimental group. The individual of food intake of the subjects was assessed by the oral questionnaire (24 hours recall) method. The quantity of raw foods used for various preparations and volumes of cooked quantities of such preparations in terms of standardized cups were noted. Body measurements were taken on all the subjects, standing height using a height measuring rod and weight in standard weighing machine.

Results: Aggressive periodontitis is seen in young individual and mostly in females; majority of the patients of both groups belongs to low socioeconomic group. Body mass index which is a reflection of nutritional status of an individual indicated that chronically energy deficient subjects in experimental group appeared to be higher. The average food and nutrient intake in control group was slightly better than that of experimental group.

Conclusion: The diet survey indicated marginal and negligible deficiencies in aggressive periodontitis patients compared to controls, and this coupled with chronically energy deficiency as indicated by body mass index, calls for a detailed study of this aspect of aggressive periodontitis. The present study indicates that nutritional influences point to a needle of suspicion toward the etiology of aggressive periodontitis.

Keywords: Aggressive periodontitis, Diet survey, Body mass index, Socioeconomic status, Food stuffs.

How to cite this article: Mapare SA, Rao PK, Reddy RV, Kumar MGM, Gorthi VSSC, Raju PVK. A Comparative Clinical Evaluation of Diet Intake and Effect of Various Nutritions on Aggressive Periodontitis Patients. J Contemp Dent Pract 2013;14(5):930-938.

Source of support: Nil

Conflict of interest: None declared

\section{CLINICAL SIGNIFICANCE}

The role of nutrition in periodontitis in general and aggressive periodontitis in particular is still equivocal. Nutrition is a 'critical determinant of immune responses' due to the fact that nutrients derived from food sources such as proteins, carbohydrates, and fats as well as micronutrients, vitamins, and minerals interact with immune cells in the blood stream, lymph nodes and specialized immune system of the gastrointestinal tract. Diets that are predominantly fibrous have been considered advantageous in their ability to impart a natural cleansing action to the teeth and the periodontium.

\section{INTRODUCTION}

The relationship between nutrition and the periodontium is controversial. Many practitioners are supporters of the concept that nutrition has an influence on the onset, progression of periodontal disease as well as outcome of periodontal therapy. Although dental plaque is the major etiologic factor in periodontal disease, inadequate nutrition may alter the host response to bacterial irritants and render the host more susceptible to establishment or progression of periodontal disease. ${ }^{1}$

The impact of nutrition on the health status can be best seen by examining extreme nutritional deprivation, which is seen less common in the developed world. Hence, a scarcity of human data exists in the area of nutritional influences on the periodontium. Numerous studies have conclusively demonstrated that the increased susceptibility to infection in a malnourished individual is due is a compromise in host defense factors. ${ }^{2,3}$ The exact mechanisms by which nutritional deficiencies modify periodontal destruction have not been precisely defined. 
The following factors affected in nutritional deficiencies: ${ }^{4}$

a. Protein and urea contents of both saliva and crevicular fluid.

b. Integrity of the dentogingival barrier and the turnover of its constituent cells.

c. Mobilization and activation of PMNs in the early inflammatory response.

d. Activation of lymphocytes and the production of immunoglobulins in the immune response.

Diets that are predominantly fibrous have been considered advantageous in their ability to impart a natural cleansing action to the teeth and the periodontium. With coarse diets, vigorous mastication is needed and the plaque that does form approximally tends to be toward the cleansable buccal and lingual surfaces of the teeth. Significant deposits do not accumulate beneath the contact points in sites that are associated with the onset of periodontal disease. However, coarse and granular diets can predispose to direct traumatic injury to the supporting tissues, most likely seen in the approximal regions where food impaction occurs. 5,6

Nutrition has both direct and indirect effects on the development and composition of plaque biofilm. ${ }^{7}$

The primary mechanism by which nutrition impacts the biofilm is through a direct supply of specific nutrients (such as sucrose) as substrates for energy, nitrogen, or carbon for the bacteria. An example of this is the introduction of excess glucose to a plaque biofilm, which has been shown to result in an increased rate of bacterial growth in the early stages of biofilm development.

The second mechanism by which nutrition has an (indirect) impact on plaque biofilm is by having an effect on the production of metabolic byproducts from one organism that provide nutrients for other organisms.

The epidemiologic and clinical data suggest that nutritional deficiencies alter immune response and increase the risk of infection. Most clinical studies of the impact of nutrition on the immune system in humans, however, have been complicated by multiple nutrient deficiencies as well as by infection. Thus, data from animal studies along with the clinical data have been useful in arriving at a consensus of how single nutrients affect the immune system. ${ }^{8,9}$

Proteins are the constituents of organic matrices of all the dental tissues including alveolar bone and periodontal ligament. The integrity of the periodontal ligament, the fibers of which are remodeled constantly is dependent on a protein supply. Early research has been carried out on experimental animals on the effects of both protein deprivation and supplements upon the periodontal tissues. These studies revealed dystrophic changes in the periodontal ligament, decreased cementum formation, osteoporosis, and resorption of the alveolar bone in protein deprivation and marked degeneration of periodontal support when it is combined with a soft diet. ${ }^{10,11}$

Vitamins are essential and biologically active constituents of a diet. The absence or scarcity of certain vitamins has been implicated as being a primary etiological factor in the pathogenesis of periodontal diseases.

Vitamin B was once thought to be a single nutrient that existed in extracts of rice, liver, or yeast. Researchers later discovered that these extracts contained several vitamins, which were given distinguishing numbers. Despite the erroneous belief that these vitamins have a special relationship to each other, each member of the B-complex has a unique structure and performs unique functions in the human body. ${ }^{12}$

Calcium is the most abundant the human body. Hypocalcemia and hypophosphatemia that result from dietary imbalance of these ions will produce a nutritional, secondary hyperparathyroidism, which initiates alveolar bone resorption. ${ }^{13}$

\section{MATERIALS AND METHODS}

A total of 85 patients with age group ranging from 15 to 25 years were selected from the outpatient department. The patients were divided in to 2 groups based on clinical radiographical features, patient with aggressive periodontits test group (45 patients, Fig. 1) and Control group with 40 healthy patients (Fig. 2). After ethical committee approval, the study design was verbally explained to the patients and written informed consent was obtained.

Simplified oral hygiene index (OHI-S), Russels periodontal index (RI) were recorded using a marked periodontal probe. Intraoral periapical radiographs (IOPA) were taken (Fig. 3) to see the bone loss in aggressive periodontitis group.

\section{Diet Survey}

Required training, to carry out diet survey, was taken from National Institute of Nutrition. Hyderabad. The food consumption survey was conducted in all the households of subjects both in control and experimental group. The individual of food intake of the subjects was assessed by the oral questionnaire (24 hour - recall) method. The housewife who had cooked and served the food was the respondent.

The quantity of raw foods used for various preparations and volumes of cooked quantities of such preparations in terms of standardized cups were noted. The respondent was asked to indicate the quantities of different cooked interns consumed by the individual member the previous day in terms of standardized cups. 


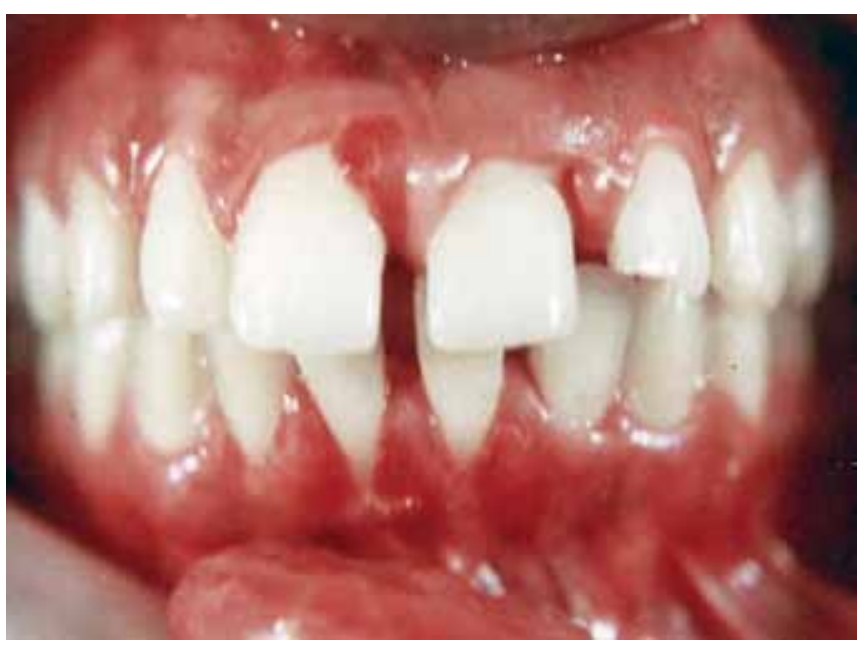

Fig. 1: Photograph showing aggressive periodontitis patient

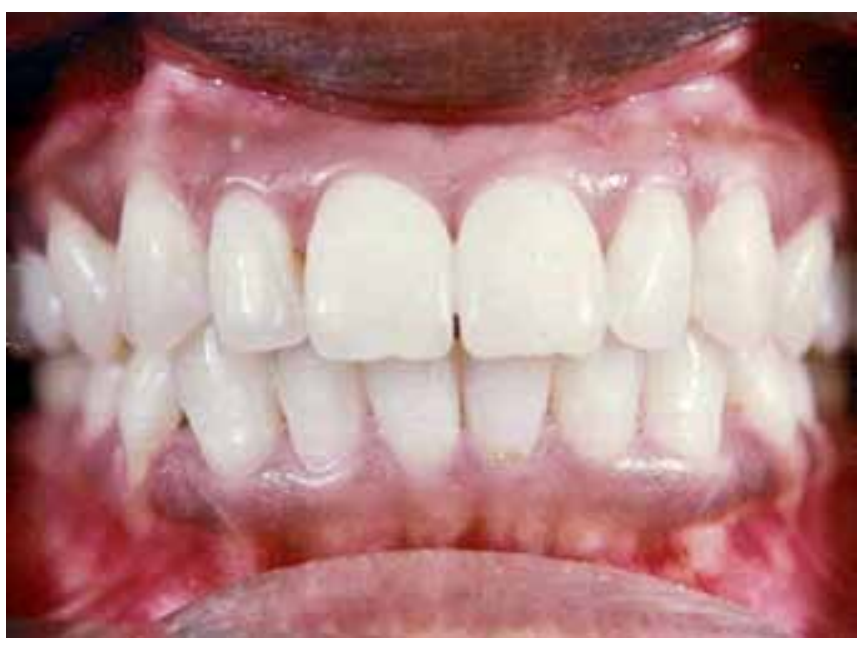

Fig. 2: Photograph showing healthy patient

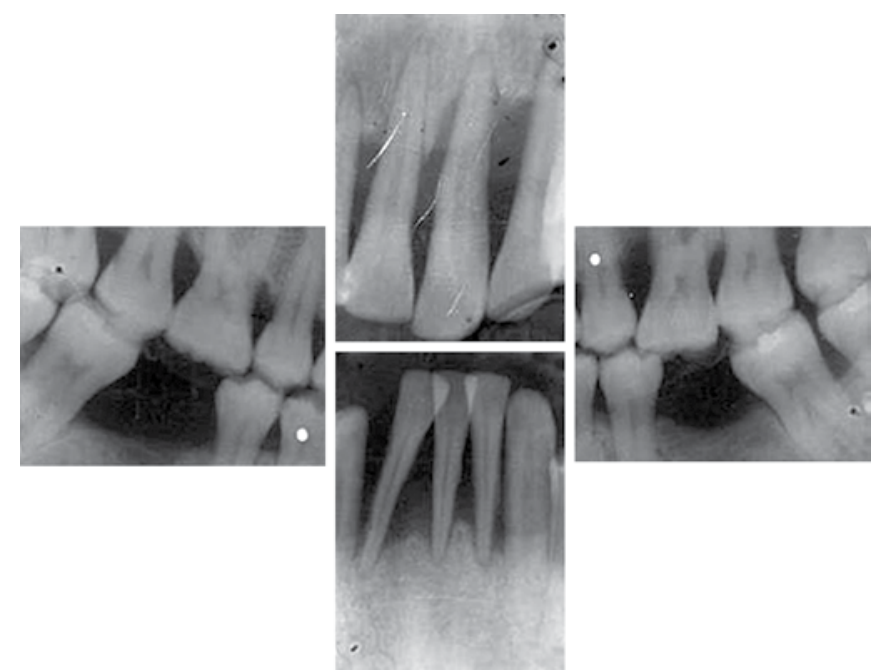

Fig. 3: IOPA showing bone loss in aggressive periodontitis patient

The amount of raw food s consumed toy individual member was calculated as follows:

\begin{tabular}{|c|c|c|c|}
\hline & $\begin{array}{l}\text { Total quantity }(\mathrm{gm}) \\
\text { of raw food cooked } \\
\text { for each time }\end{array}$ & $x$ & $\begin{array}{l}\text { Volume of cooked } \\
\text { food consumed by } \\
\text { the individual member }\end{array}$ \\
\hline
\end{tabular}

After obtaining the quantity of different raw foods consumed by individuals, the nutrients were calculated using the table of nutritive value of Indian food. The nutrients in the diet were compared with recommended dietary allowances.

\section{ANTHROPOMETRY}

Making use of the standard procedures and equipment the following body measurements were taken on all the subjects.

1. Standing height using a height measuring rod

2. Weight in standard weighing machine.

\section{BODY MASS INDICES}

Body mass indices (BMI) are used to assess the nutritional status of adults. BMI was calculated by the following formula for all subjects:

$$
\mathrm{BMI}=\frac{\text { Weight in } \mathrm{kg}}{\text { Height in meters }}{ }^{2}
$$

After calculating BMI values, the subjects both in experiment and control groups, were classified according to the following classification.

\section{RESULTS}

\section{Age Distribution (Table 1)}

The patients' age in experimental and control group varied from 15 to 25 years. The mean age was 19 years in the experimental group and 19 years in control group. In the experimental group $17.8 \%$ of cases were in 15 to 18 years age group, $48.9 \%$ in 18 to 21 age group, and $26.7 \%$ in 21 to 24 age groups. Thus, it can be seen that almost half of the Juvenile periodontitis patients were in the 18 to 21 age group, $22.5 \%$ in 21 to 24 age group and $5 \%$ in $>24$ years age group. However, there was no difference in age in the control group as compared to the experimental.

The distribution of subjects in experimental and control groups according to various age groups was not statistically significant by $\mathrm{X}$-test $(\mathrm{p}>0.05)$. It can be noticed that about

\begin{tabular}{lrrrrr}
\multicolumn{3}{c}{ Table 1: Distribution of subjects according to } \\
age and group
\end{tabular}

Note: The distribution of subjects in experimental group according to different age groups is not significantly different from that of control group subjects by chi-square test $(p=0.92)$ 
A Comparative Clinical Evaluation of Diet Intake and Effect of Various Nutritions on Aggressive Periodontitis Patients

\begin{tabular}{|c|c|c|c|c|c|c|c|c|}
\hline \multirow[t]{2}{*}{ Age (years) } & \multicolumn{4}{|c|}{ Males } & \multicolumn{4}{|c|}{ Females } \\
\hline & Experimental & $\%$ & Control & $\%$ & Experimental & $\%$ & Contrrol & $\%$ \\
\hline $15-18$ & 1 & 2.3 & 1 & 2.5 & 7 & 15.5 & 8 & 20.0 \\
\hline $18-21$ & 5 & 11.2 & 7 & 17.5 & 17 & 37.8 & 13 & 32.5 \\
\hline $21-24$ & 4 & 8.9 & 2 & 5.0 & 8 & 17.8 & 7 & 17.5 \\
\hline$>24$ & - & & 1 & 2.5 & 3 & 6.7 & 1 & 2.5 \\
\hline
\end{tabular}

1. Age distributions of males in experimental and control gruops are not statistically significant by chi-square $\left(\chi^{2} c, 1=0.0382, p>0.05\right) ; 2$. Age distribution of females in experimental and control grups were not statistically significant by chi-square $\left(\chi^{2} c, 2=0.516 p>0.05\right)$

$90 \%$ of subjects were below the age of 24 years. It supports the hypothesis that the prevalence of juvenile periodontitis occurs in teenagers and younger age groups.

Sex distribution (Table 2): in the present study, $77.7 \%$ of the patients were females giving a male female ratio 1:3.5.

\section{Socioeconomic Status (Table 3)}

The family income of the subjects from all sources was assessed and computed as income per day/head (Total income in year/(no. of family members $\times 365$ ). After computing the income per day, the families are distributed according to various income groups and the results are presented. It was observed that $69 \%$ of the subjects had the PCI/day in experimental group was less than ₹ 10/-, while in control it was $55 \%$. The mean per capita income of experimental group (₹ 9.29) was not statistically significant from that of control group (₹ 11.32) by 'student t-test' $(p>0.05)$. It appears majority of the families belonged to low socioeconomic group with percapita income per day was less than ₹ 10/-.

\section{Individual Status (Occupation)}

The nature of the occupation of the subjects was obtained and the distribution of subjects according to occupation is presented in Table 4. It was observed, in experimental and control group, that $75 \%$ of the subjects were students, $7 \%$ unemployed, $10 \%$ Government servants and $6 \%$ housewives

\begin{tabular}{lcrr}
\multicolumn{4}{c}{ Table 3: Distribution of subjects and per capita income per day } \\
\hline$P C l$ & $\begin{array}{c}\text { Experimental } \\
(n=45)\end{array}$ & $\begin{array}{c}\text { Control } \\
(n=40)\end{array}$ & $\begin{array}{c}\text { Total } \\
(n=85)\end{array}$ \\
\hline $1-2$ & - & 2.5 & 1.2 \\
$2-5$ & 15.6 & 5.0 & 10.6 \\
$5-10$ & 53.3 & 47.5 & 50.6 \\
$>10$ & 31.1 & 45.0 & 37.6 \\
\hline Mean \pm SD & $9.29 \pm 6.02$ & $11.32 \pm 6.01$ & \\
\hline
\end{tabular}

1. The distribution of subjects according to percapita income $(\mathrm{PCl})$ per day is same both in experimental and control groups by $\chi^{2}-$ test $\left(\chi^{2}, 2=2.396 ; p>0.05\right)$;

2. The mean percapita income in experimental group is not significantly different from that of control by student $t$-test $\left(t_{c}, 83\right.$ $=1.55, \mathrm{p}>0.05$ )

\begin{tabular}{lcrr}
\multicolumn{4}{c}{ Table 4: Percent distribution of subjects according to } \\
occupation \\
& $\begin{array}{c}\text { Experimental } \\
(n=45)\end{array}$ & $\begin{array}{l}\text { Control } \\
(n=40)\end{array}$ & $\begin{array}{c}\text { Total } \\
(n=85)\end{array}$ \\
\hline Student (1) & $33(73.4)$ & $31(77.5)$ & $64(75.2)$ \\
Business (2) & $2(4.4)$ & - & $2(2.4)$ \\
Unemployed (3) & $3(6.7)$ & $3(7.5)$ & $6(7.1)$ \\
Govt. employee (4) & $5(11.1)$ & $3(7.5)$ & $8(9.4)$ \\
\hline Housewife (5) & $2(4.4)$ & $3(7.5)$ & $5(5.9)$
\end{tabular}

Note 1: Figures in parenthesis indicate percentage;

2. Distribution of subjects according to occupation both in experimental and control groups are same $\left(\chi^{2} c, 1=0.198\right.$, $p>0.05)$

and the remaining subjects were petty business men (2\%). The distribution of subjects in experimental and control groups according to occupation was similar, and these distributions were not statistically significant by $\chi^{2}$ test $(p>0.05)$. The demographic as well as socioeconomic particulars so far presented indicate that the subjects in experimental and control groups are more or less similar and hence are comparable.

\section{Body Mass Index (Table 5)}

The proportion of chronically energy deficient adults (BMI 18.5 ) in experimental group was $27 \%$ against $15 \%$ in the control group, but statistically not significant, whereas the proportion of normal subjects was significantly higher in control group compared to experimental group. The percentage of overweight and obese subjects was slightly higher in the experimental group, hence the nutritional status of the aggressive periodontitis generally tended to be poor as compared to that of normal counter parts.

\begin{tabular}{|c|c|c|c|c|}
\hline & \multicolumn{2}{|c|}{$\begin{array}{l}\text { Experimental } \\
\quad(n=45)\end{array}$} & \multicolumn{2}{|c|}{$\begin{array}{l}\text { Control } \\
(n=40)\end{array}$} \\
\hline & No. & $\%$ & No. & $\%$ \\
\hline$<18.5$ & 12 & 26.7 & 6 & 15.0 \\
\hline $18.5-25.0$ & 27 & 60.0 & 32 & $80^{*} .0$ \\
\hline$>25.0$ & 6 & 13.3 & 2 & 5.0 \\
\hline
\end{tabular}

${ }^{*}$ The proportion of normal subjects in control group was higher than that of experimental group by small sample proportion t-test $(p<0.05)$ 


\begin{tabular}{lccc} 
& Table 6: Mean foodstuff intake (gm/day) according to groups & \\
\cline { 2 - 3 } Foodstuffs & Experimental $(n=45)$ & Control $(n=40)$ & $R D A$ \\
\cline { 2 - 3 } Cereals & Mean \pm SD & Mean \pm SD & 410 \\
Pulses & $302.06 \pm 73.09$ & $299.59 \pm 75.70$ & 36 \\
GLVs & $48.45 \pm 43.11$ & $41.60 \pm 42.60$ & 36 \\
Roots and tubers & $7.84 \pm 25.19$ & $2.59 \pm 4.68$ & 45 \\
Other vegetables & $58.02 \pm 70.65$ & $78.48 \pm 79.27$ & 54 \\
Nuts and oils & $24.01 \pm 39.42$ & $31.29 \pm 45.80$ & \\
Cond. and spices & $1.91 \pm 2.05$ & $3.54 \pm 4.38$ & \\
Fruits & $12.01 \pm 12.34$ & $13.22 \pm 10.65$ & \\
Flesh foods & $36.06 \pm 55.24$ & $66.93 \pm 75.26$ & \\
Milk and milk products & $38.35 \pm 88.33$ & $59.68^{*} \pm 84.12$ & 135 \\
Sugar and Jaggery & $160.09 \pm 116.72$ & $170.03 \pm 112.93$ & $35.82 \pm 20.63$ \\
Fats and oils & $33.34 \pm 23.62$ & $29.91 \pm 14.74$ & 36 \\
\hline
\end{tabular}

*The mean food intakes of subjects in control group was significantly higher than that of experimental group by modified t-test $(p<0.05)$

\section{Food Consumption (Tables 6 and 7, Graphs 1 to 5)}

Oral questionnaire (24 hour-recall) method of diet survey was carried out. The range in the quantity of foodstuffs consumed is also presented as variation in individual intakes is common, particularly in urban setting. Foodstuffs generally consumed in urban areas had been broadly classified into 13 major groups. They are cereals, pulses, green leafy vegetables, roots and tubers, other vegetables, nuts and oil seeds, condiments and spices, fruits, flesh foods, milk and milk products, sugar and jaggery and fats and oils. The average age of the subjects on whom diet survey was carried out both in experimental and control group was about 19 years. Besides, higher proportions of subjects were women and students. Hence, their intakes were compared with the RDA/RDI values of young woman.

\section{Cereals}

The mean consumption of cereals in experimental and control groups was $302 \mathrm{gm}$ and $300 \mathrm{gm}$ respectively. The intakes in both groups were below the recommended value of $410 \mathrm{gm}$.

\section{Pulses}

The average intake of pulses in the experimental group was $48 \mathrm{gm}$, where as it was $42 \mathrm{gm}$ in control group. Both the groups had intakes above the recommended level of $36 \mathrm{gm}$.

\section{Green Leafy Vegetables}

The average consumption of green leafy vegetables (a rich and inexpensive source of iron and beta carotene) was very low in both the control and experimental groups compared to the suggested level of $40 \mathrm{gm}$. It was $8 \mathrm{gm}$ in experimental group and $3 \mathrm{gm}$ in control group.

\section{Roots and Tubers}

The mean intake of roots and tubers was $58 \mathrm{gm}$ in experimental group and $78 \mathrm{gm}$ in control group. The average consumption in both groups was more than the suggested levels of $45 \mathrm{gm}$.

\begin{tabular}{|c|c|c|c|}
\hline \multirow[t]{2}{*}{ Nutrient } & Experimental $(n=45)$ & Control $(n=40)$ & \multirow[t]{2}{*}{$R D A$} \\
\hline & Mean \pm SD & Mean \pm SD & \\
\hline Energy (Kcal) & $18.71+408.24$ & $2007.71+366.16$ & 2060 \\
\hline Proteins (gm) & $48.19+18.68$ & $53.33+19.71$ & 63 \\
\hline Calcium (mg) & $608.77+266.96$ & $656.63+272.50$ & 500 \\
\hline Iron (mg) & $10.64+6.01$ & 11.164 .30 & 30 \\
\hline Vitamin A ( $\mu \mathrm{g})$ & $207.31+106.41$ & $281.12+179.16$ & 600 \\
\hline Thiamine (mg) & $0.91+0.38$ & $0.98+0.37$ & 1.0 \\
\hline Riboflavin (mg) & $0.71+0.21$ & $0.78+0.24$ & 1.2 \\
\hline Niacin (mg) & $13.34+7.19$ & $14.31+7.12$ & 14 \\
\hline Vitamin C (mg) & $38.45+31.72$ & $47.50+38.33$ & 40 \\
\hline
\end{tabular}

*The mean intake of vitamin A in control subjects is significantly higher than that of experiment group subjects by modified t-test $(p<0.05)$ 


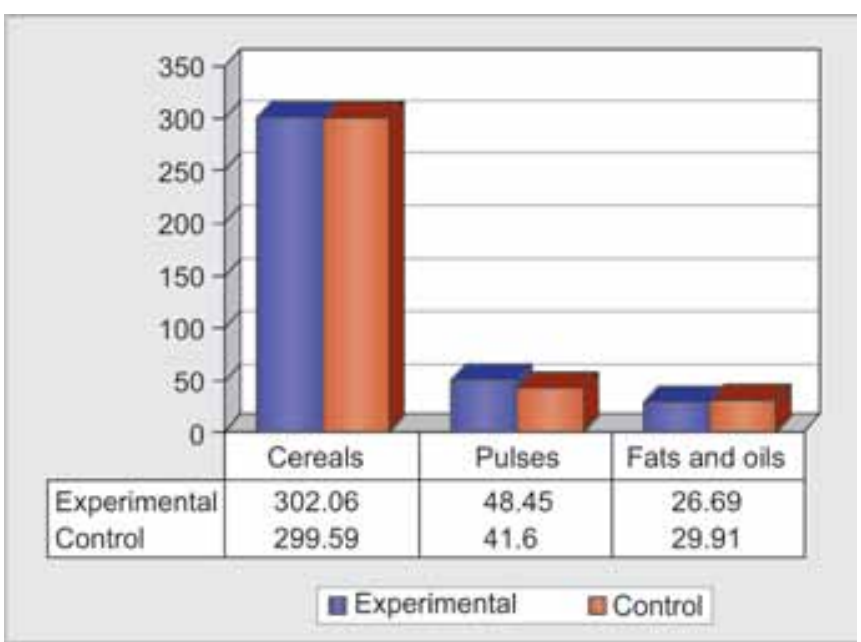

Graph 1: Mean intake of foodstuffs (gm) by groups

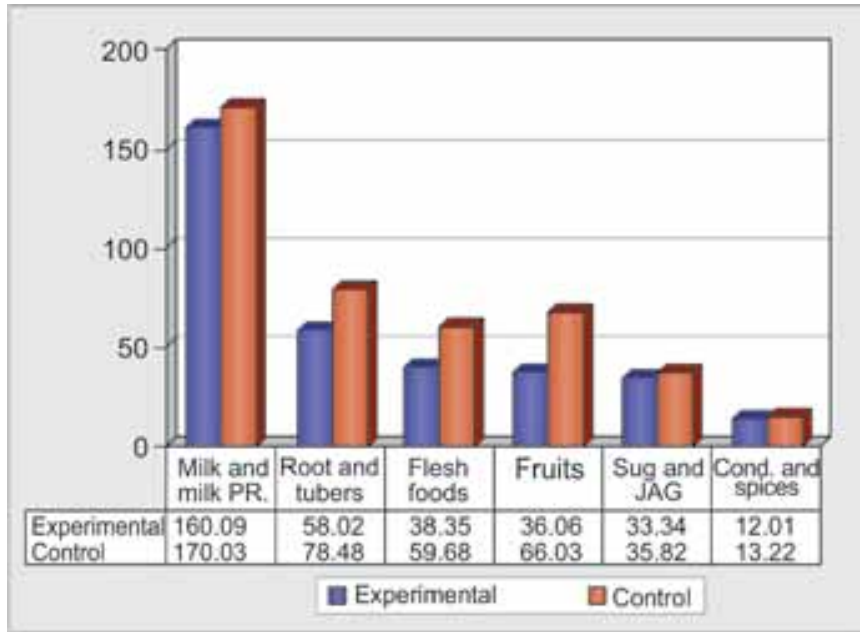

Graph 2: Mean intake of foodstuffs (gm) by groups

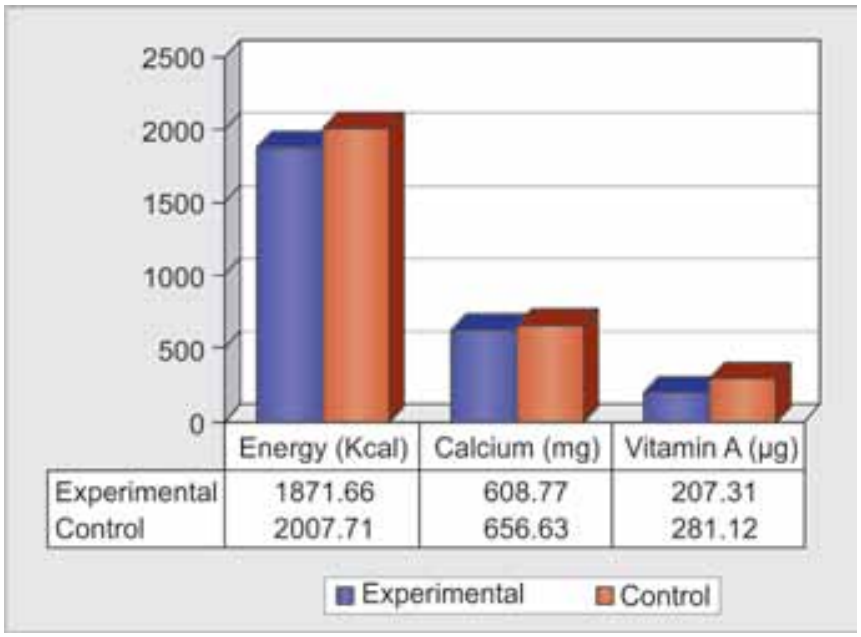

Graph 3: Mean intake of nutrients by groups

\section{Other Vegetables}

The average consumption of other vegetables was $24 \mathrm{gm}$. in experimental group and. $31 \mathrm{gm}$ in control group. Average intakes in both the groups, were much lower than the recommended intakes of $54 \mathrm{gm}$.

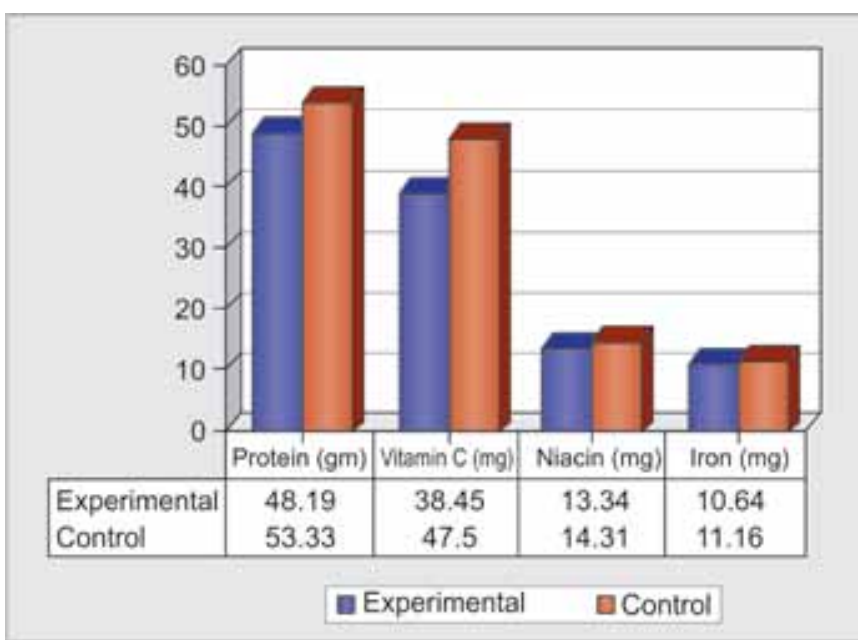

Graph 4: Mean intake of nutrients by groups

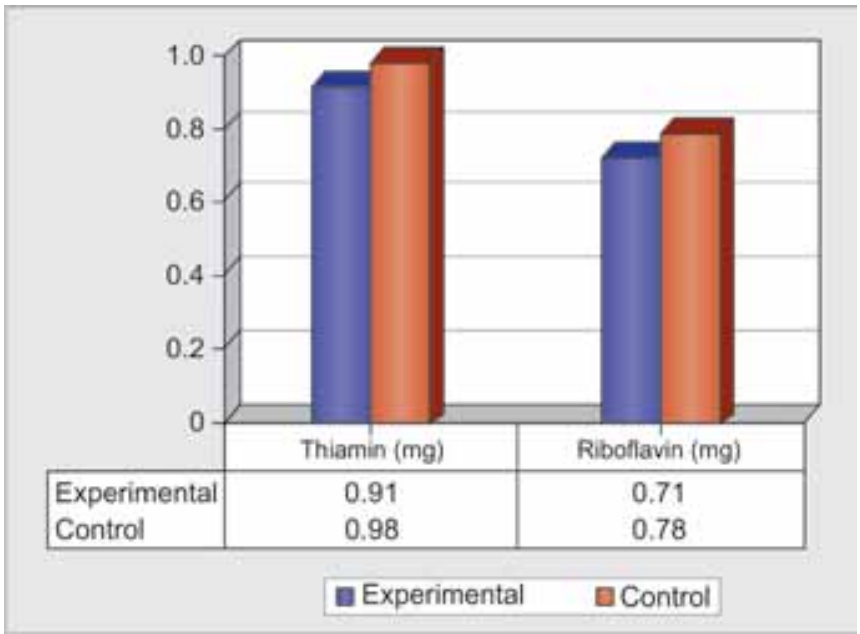

Graph 5: Mean intake of nutrients by groups

Fish Food

The mean consumption of flesh foods (including fish, meat, egg and poultry) was slightly higher in the control group (60 gm) as compared to the experimental group (38 gm). The difference between these means was not statistically significant.

\section{Milk and Milk Products}

The mean intake of milk and milk products in experimental group was $160 \mathrm{gm}$ while in control group it was $170 \mathrm{gm}$. The mean intakes was above the recommended value of $135 \mathrm{gm}$.

\section{Sugar and Jaggery}

The mean intake of sugar and jaggary in experimental group was $33 \mathrm{gm}$. while it was $36 \mathrm{gm}$ in control group. The mean intakes in both the groups were above the recommended value of $27 \mathrm{gm}$. 


\begin{tabular}{llllll}
\multicolumn{3}{c}{ Table 8: Maximum and minimum intake of food stuffs (gm/day) } \\
according to groups
\end{tabular}

\section{Fats and Oils}

The mean consumption of fats and oils in experimental group 27 and $30 \mathrm{gm}$ in control group which is below recommended value of $36 \mathrm{gm}$.

The average food intake in control group was slightly better than in the experimental group, even though the mean intakes are not statistically significant by modified t-test, In some of the cases, the standard deviations are more than mean values, thereby indicating high intraindividual variation.

\section{Nutrient Intake (Table 8)}

Using food consumption tables (ICMR, 1991), nutritive values of food stuffs consumed by the subjects both in experimental and control group were computed.

\section{Energy}

The mean intake of energy in experimental subjects was 1872 real, while in control group it was 2008 real. In none of the groups, the mean intakes were above the suggested level of 2060 real. On average, the subjects in experimental group consumed $136 \mathrm{Kcal}$ less than that of subjects in control group. Statistically, this difference of 136 real was not significant, but biologically it may be of significance.

\section{Protein}

The average intake in both groups was 48.2 and $53.3 \mathrm{gm}$ respectively. These intakes were below the RDI value of $63 \mathrm{gm}$.

\section{Calcium}

The mean consumption of calcium in experimental group $609 \mathrm{mg}$ and in control group $657 \mathrm{mg}$. This consumption is higher than RDI value of $500 \mathrm{mg}$.

\section{Iron}

The mean consumption of iron in experimental group $10.6 \mathrm{mg}$ and in control group $11.16 \mathrm{mg}$. In both the groups iron was about $11 \mathrm{mg}$. and this average was lower than the recommended value of $30 \mathrm{mg}$.

\section{Vitamin A}

In none of the groups, the average intake of vitamin A was comparable to EDI of $600 \mathrm{mg}$. In experimental group the deficit was 651 while in control group it was 531 .

\section{Thiamine}

In both the groups, the consumption of thiamine was less than suggested value of $1.00 \mathrm{mg}$. The deficit in experimental group was $9 \%$ where as in control group it was $2 \%$.

\section{Riboflavin}

In all the groups, the average consumption of riboflavin was less than the recommended value of $1.2 \mathrm{mg}$, The deficit in experimental subjects was $41 \%$ while it was $35 \%$ in control group,

The nutrient intakes in control group were slightly higher than that of experimental group but the difference were not statistically significant.

Analysis of variance (ANOVA) showed that most of the differences observed were marginal and no significant differences within and between the groups regarding food stuffs and nutrients were noticed in both groups.

\section{DISCUSSION}

The role of nutritional deficiencies as an etiologic or contributing agent of inflammatory periodontal disease has been a matter of debate. Higher prevalence of periodontal 
disease has been observed in underdeveloped and under privileged communities pointing to a poor nutritional background. On the other hand many believe that while a principal relationship could be established between oral hygiene and periodontal disease score, no strong association between any specific nutritional diseases could be demonstrated when the effects of age and hygiene were 72 considered simultaneously. ${ }^{14,15}$

The study of aggressive periodontitis in 45 patients as compared to an almost equal number of age and sex matched controls reveal that most of the juvenile periodontitis patients were in the adolescent age group with a mean age of 19 years. Ninety percent of the patients were below the age of 20 years and were already having classical manifestations of the disease and if were examined retrospectively would have perhaps, had its onset in the early teens. The age incidence of aggressive periodontitis has been reported to vary according to different authors. ${ }^{16,17}$ The present study is close to some of the Indian studies as far as age range of patients is concerned.

\section{Sex Distribution}

Aggressive periodontitis seems to be more prevalent in females than in men. In the present study, $77.7 \%$ of the patients were females giving a male; female ratio of 1:3.5. This has been one area with most divergent opinions.

The variation in sexual predilection is because of differences in criteria and. changing concept about the existence of this condition as a clinical entity. As far as this study is concerned, using the most exacting and demanding criteria in the background of the present day understanding of aggressive periodontitis, it is prevalent in a greater number of females than males and this sex predilection is an important factor in the existing knowledge regarding aggressive periodontitis.

It has been an observation of many clinicians that aggressive periodontitis patients are lean and thin built. This was put to test in the present study by utilizing BMI which is a fair reflection of the person's stature. The proportion of chronically energy deficient adults in experimental group was slightly more than in control group. Although this is not statistically significant, it is a pointer toward a leaner physique in aggressive periodontitis. Conversely, the proportion of normal subjects ( 18.5 to 25.0 ) was significantly higher in control group as compared to experimental group $(p<0.05)$ indicating that there were more number of normal subjects in control group compared to experimental group. ${ }^{18}$

\section{Food Consumption}

Using oral questionnaire (24-hour recall) method, a diet survey was carried out and the pattern of food consumption of 13 food groups was analyzed. The adequacy of diet as compared to the EDA/RDI were analyzed and the nutrient values of the diets consumed were obtained from computer analysis. The food consumption in experimental and control group did not vary significantly. The consumption of cereal, green leafy vegetables and other vegetables and fats oils was below the recommended values both in experimental and control groups and not confined to juvenile periodontitis patients only. The consumption of pulses, milk and milk products and roots 8 tubers was adequate and did not show any differences between groups. ${ }^{19,20}$

There is a marked deficiency of intake of vitamin A with the experimental group showing a deficit of 555 and the control group showing a deficit of 531. Vitamin A supplementation is reported to improve the hematological condition in childrens and the low values of vitamin. The observation is that intervention with vitamin A lead to increased hemoglobin concentration is pertinent to quote here and consider iron and vitamin A supplementation in aggressive periodontitis patients. ${ }^{21}$

The intake of vitamin $B_{1}$ and $B_{12}$ is deficient, marginally in the case of thiamine and moderately severe in riboflavin. However, the deficit is again seen in both the groups and not directed against juvenile periodontitis patients alone. ${ }^{22}$ The nutrient intakes in control group are slightly higher than that of experimental group but the differences are not statistically significant. malnutrition and Kwashiorkor are reported to cause necrotizing ulcerative gingivitis and predisposed to development of periodontal disease and protein supplementation combined with dental prophylaxis gave evidence of the most favorable results. ${ }^{23}$

\section{CONCLUSION}

The diet survey indicated marginal and negligible deficiencies in aggressive periodontitis patients compared to controls, and this coupled with chronically energy deficiency as indicated by body mass index, calls for a detailed study of this aspect of aggressive periodontitis. The present study indicates that nutritional influences point to a needle of suspicion toward the etiology of aggressive periodontitis but the evidence available so far is neither conclusive nor statistically significant. A study with a larger sample with nutritional probing only as the sole objective will clinch the issue of the role of nutrition in juvenile periodontitis and chronic periodontal diseases.

\section{REFERENCES}

1. Robert ES. Nutrition and periodontal disease. Dent Clin N Am 2005;49:595-610.

2. Enwonwu CO, Phillips RS, Falkler WA Jr. Nutrition and oral infectious diseases: state of the science. Compend Contin Educ Dent 2002;23(5):431-438. 
3. Neiva RF, Steigenga J, Al-Shammari KF, et al. Effects of specific nutrients on periodontal disease onset, progression and treatment. J Clin Periodontol 2003;30(7):579-589.

4. Boyd LD, Madden TE. Nutrition, infection, and periodontal disease. Dent Clin N Am 2003;47(2):337-354.

5. Trumbo P, Schlicker S, Yates AA, et al. Dietary reference intakes for energy, carbohydrate, fiber, fat, fatty acids, cholesterol, protein and amino acids. J Am Diet Assoc 2002;102(11):1621-1630.

6. Vogel RI. and Wechsler SM. Nutritional survey of patients with moderate to severe periodontitis. Clinical and Preventive Dentistry 1979;5:35-38.

7. Baumgartner S, Imfeld T, Schicht $\mathrm{O}$, et al. The impact of the stone Age diet on gingival conditions in the absence of oral hygiene. J Periodontol 2009;80:759-768.

8. Osborn MO, Hornbuckle C, Stumbo P. Nutritional evaluation of food intake records of periodontal patients. Journal of Periodontology1977;48:659-662.

9. Chandra RK. Nutrition and the immune system: an introduction. Am J Clin Nutr 1997;66:440-443.

10. Al-Zahrani MS. Increased intake of dairy products is related to lower periodontitis prevalence. J Periodontol 2006;77:289-294.

11. Nishida M, Grossi SG, Dunford RG, Ho AW, Trevisan M, Genco RJ. Dietary vitamin C and the risk for periodontal disease. J Periodontol 2000;71:1215-1223.

12. Yates AA, Schlicker SA, Suitor CW. Dietary reference intakes: the new basis for recommendations for calcium and related nutrients, B vitamins, and choline. Journal of the American Dietetic Association1998;98:699-706.

13. Smith SM, Wastney ME, O'Brien KO, et al. Bone markers, calcium metabolism, and calcium kinetics during extendedduration space flight on the mir space station. J Bone Miner Res 2005;20:208-218.

14. Sheiham A, et al. The relationship among dental status, nutrient intake and nutritional status in older people. J Dent Res 2001;2: 408-413.

15. Milward MR, Chapple ILC. The role of diet in periodontal disease. Dental Health 2013;52(3):18-21.

16. Yoshihiro $\mathrm{S}$, et al. Intake of dairy products and periodontal disease: The Hisayama Study. J Periodontol 2008;79:131-137.

17. Kaining Liu, et al. Elevated plasma calcifediol is associated with aggressive periodontitis. J Periodontol 2009;80:1114-1120.

18. Van der Velden U, Kuzmanova D, Chapple. ILC. Micronutritional approaches to periodontal therapy. J Clin Periodontol 2011;38 (S11):142-158.

19. Chapple ILC, Milward MR, Ling-Mountford N, et al. Adjunctive daily supplementation with encapsulated fruit, vegetable and berry juice powder concentrates and clinical periodontal outcomes: a double-blind RCT. J Clin Periodontol 2012;39:62-72.

20. Subar AF, Heimendinger J, Patterson BH, Krebs-Smith SM, Pivonka E, Kessler R. Fruit and vegetable intake in the United States: the baseline survey of the Five A Day for Better Health Program. American Journal of Health Promotion 1995; 9:352360.

21. White DA, Tsakos, Pitts, GNB, Fuller E, et al. Adult Dental Health Survey 2009: common oral health conditions and their impact on the population. Brit Dent J 2012;213:567-572.

22. Alvarez OM, Gilbreath RL. Thiamine influence on collagen during the granulation of skin wounds. Journal of Surgical Research 1982;32:24-31.

23. Melnick SL, Navia JM, Cogen RB, Roseman JM. A case-control study of plasma ascorbate and acute necrotizing ulcerative gingivitis. Journal of Dental Research 1988;5:855-860.

\section{ABOUT THE AUTHORS}

\section{Sagar Arjun Mapare}

Reader, Department of Orthodontics, HSRSM Dental College and Hospital, Hingoli, Maharashtra, India

\section{P Krishna Rao (Corresponding Author)}

Professor and Head, Department of Periodontics, HSRSM Dental College and Hospital, Hingoli, Maharashtra, India, e-mail: doctorpydi@gmail.com

\section{R Vamshidhar Reddy}

Professor and Head, Department of Orthodontics, HSRSM Dental College and Hospital, Hingoli, Maharashtra, India

\section{MG Manoj Kumar}

Professor and Head, Department of Pedodontics, Sibar Institute of Dental Sciences, Guntur, Andhra Pradesh, India

\section{VSS Chandana Gorthi}

Reader, Department of Periodontics, HSRSM Dental College and Hospital, Hingoli, Maharashtra, India

\section{PV Krishnam Raju}

Professor, Department of Periodontics, Kalinga Institute of Dental Sciences, Bhubaneswar, Odisha, India 